\title{
CDISC SEND Respiratory Test Code Terminology
}

National Cancer Institute

\section{Source}

National Cancer Institute. CDISC SEND Respiratory Test Code Terminology. NCI

Thesaurus. Code C120534.

Terminology associated with the respiratory test code codelist of the Clinical Data Interchange Standards Consortium (CDISC) Standard for the Exchange of Non-clinical Data (SEND). 